\title{
Papel do judiciário na segurança nacional
}

\author{
Soraya Regina Gasparetto Lunardi ${ }^{1}$
}

\begin{abstract}
Sumário: Introdução; 1. Meios de realização do direito à segurança; 1.1. Segurança pela força; 1.2. Segurança pelo bem-estar; 1.3. Dependência conceitual da segurança; 2 . Aspectos principais do direito à segurança; 2.1. Tutela estatal da segurança: seguridade social, segurança no trabalho, garantia da propriedade privada, segurança pública; 2.2. Segurança dos indivíduos em relação a interferências estatais; Conclusão; Referências.
\end{abstract}

Resumo: O presente estudo analisa a efetividade das políticas públicas e os limites da intervenção estatal em nome do direito fundamental à segurança. Para tanto, são analisadas as várias faces do direito à segurança, especialmente como expressão de bem estar social, seus limites econômicos e o papel do judiciário para a sua concretização. Um dos problemas para a concretização do direito à segurança é que ela se efetiva pelas limitações impostas ao direito de liberdade, que também é um direito assegurado no texto constitucional. As formas como o Estado e o poder judiciário vêm estabelecendo essa harmonia e os possíveis abusos cometidos em nome da segurança são analisados criticamente.

Palavras-chave: segurança; políticas públicas; segurança pública

\begin{abstract}
This paper examines the effectiveness of public policies and the limits of state intervention on behalf of the fundamental right to security. Both are analyzed for the various faces of the right to security especially as an expression of their social welfare and economic limits of the judicial role to its realization. One problem for the realization of the right to security is that it is effective for the limitations on the right of freedom, which is also a right guaranteed in the constitutional text. The ways the state and the judiciary are establishing this harmony and the possible abuses in the name of security are examined critically.
\end{abstract}

Keywords: security; public policies; public security.

\footnotetext{
1 Soraya Gasparetto Lunardi - Doutora em Direito pela Pontifícia Universidade Católica de São Paulo, Pós-Doutora pela Universidade de Athenas - Grécia. Coordenadora e professora do Mestrado em Direito da UNIMAR. Coordenadora do Núcleo de Pesquisa Docente da Instituição Toledo de Ensino de Bauru.
} 


\section{Introduçãa $0^{2}$}

No direito constitucional brasileiro, o direito à segurança apresenta uma interessante duplicidade, pois constitui ao mesmo tempo, direito "negativo" e "positivo". ${ }^{3}$ Os principais dispositivos constitucionais que regulamentam o direito a segurança são os seguintes.

Artigo 5으, caput da Constituição Federal: "Todos são iguais perante a lei, sem distinção de qualquer natureza, garantindo-se aos brasileiros e aos estrangeiros residentes no País a inviolabilidade do direito [...] à segurança". Nesse caso, temos um clássico direito negativo (de defesa), sendo a segurança dos titulares do direito garantida contra possíveis intervenções do Estado que possam ameaçá-la.

O artigo $6^{\circ}$ da Constituição Federal proclama a segurança como direito social: "São direitos sociais [...] a segurança [...], na forma desta Constituição". Esse direito possui duas dimensões territoriais. ${ }^{4}$ Há a perspectiva da segurança externa, que se refere à defesa do Estado, à segurança nacional (integridade territorial, preservação da soberania e das instituições estatais) e a perspectiva interna que se refere à preservação dos direitos de todos contra as ameaças provenientes da sociedade e do próprio Estado. A segurança enquanto direito que permite exigir do Estado uma atuação positiva (prestação material e normativa) encontra-se especificada no artigo 142 caput da Constituição Federal, que estabelece como finalidade das Forças Armadas a preservação da segurança externa. Já o artigo 144 da Constituição Federal refere-se à segurança interna, como dever de Estado que é confiado principalmente às autoridades policiais, e consiste na "preservação da ordem pública e da incolumidade das pessoas e do patrimônio".

Segurança significa "tranqüilidade e ausência de perigo e de medo de agressão a bens e direitos". ${ }^{5} \mathrm{Ou}$ ainda "estado que resulta da ausência de impressão de perigo". ${ }^{6}$ Tais definições são de cunho psicológico e inevitavelmente subjetivo. Como objetivar e medir a segurança, tornando-a juridicamente exigível?

2 Pesquisa realizada com os alunos do Núcleo de Pesquisa docente: Yudi Marcel Ramos Santi e Raquel Pampado.

3 S, 2007, p. 343.

4 S, 2007, p. 343.

5 S, 2007, p. 343-344.

6 A, 1999, p. 707. 
$\mathrm{O}$ direito à segurança possui também duas dimensões em relação aos meios utilizados para sua garantia. Analisaremos isso em seguida, diferenciando entre a segurança pela força e a segurança pelo bem-estar.

\section{Meios de realização do direito à segurança}

\subsection{Segurança pela força}

A ideia de ordem pela força e violência é inerente ao conceito de segurança. A segurança que objetiva preservar determinada forma de organização social: integridade territorial, estabilidade do sistema político e econômico, proteção das pessoas e de seu patrimônio. Assim sendo, a segurança apresenta caráter conservador: instituições, direitos e interesses são garantidos, se necessário com meios repressivos contra eventuais agressões. ${ }^{7}$ Nessa linha, podemos indicar as seguintes formas de atuação do Estado para estabelecer segurança:

- Legislação. A promessa de segurança no sentido de imposição e manutenção da ordem faz parte da essência do Estado e justifica sua atuação. A atuação do Estado para manter a ordem se dá, via de regra, pela aplicação ou ameaça de aplicação das leis, servindo a punição como meio para impedir o desvio "criminal". O medo da insegurança é um fator de aumento do poder estatal e de restrição da liberdade individual.

- Polícia. Se a lei atua como forma indireta de repressão, justificando-se pela promessa de segurança, as corporações policiais aplicam formas diretas de vigilância e repressão, tendo como justificativa a mesma promessa: fazer cumprir o conjunto de leis e assegurar a ordem social.

- Forças armadas. A proteção da ordem social de ameaças externas tanto diretas (invasões, guerras) como indiretas (espionagem, intromissões de agentes estrangeiros em processos de decisões políticas) é finalidade primordial das Forças Armadas. Nesse caso, a promessa de segurança ultrapassa o interesse pessoal, objetivando garantir a macrossegurança.

7 S, 2007, p. 344. 
Essa classificação deixa claro que não podemos pensar no direito fundamental à segurança sem analisar o poder exercido pelo Estado através da força. $\mathrm{O}$ medo alimenta a força do Estado em relação à segurança, especialmente em épocas de instabilidade e de aumento da violência social, gerando à atuação do Estado uma sensação de estabilidade.

Para os críticos, essa exigência de ordem, através de medidas coercitivas, têm como consequência a fabricação de uma "humanidade", eliminando indivíduos pelo bem da espécie, sacrificando partes em benefício do todo. Em paralelo, observa-se a uniformização de gostos, desejos e formas de agir, num processo de despersonalização que objetiva eliminar as diferenças, impondo o conformismo. ${ }^{8}$

"Liberdade e insegurança estão em relação recíproca, uma vive da outra". ${ }^{9}$ A liberdade faz o homem soberano. Isso pode tanto garantir como ameaçar a segurança. Certamente, a livre atuação pode afetar direitos dos demais, gerando insegurança. ${ }^{10}$ Mas o homem que é constantemente vigiado e potencialmente ameaçado por aparelhos estatais não somente sente-se ameaçado em sua privacidade e liberdade de ação, mas também em sua segurança, podendo estar sujeito a medidas arbitrárias do Estado. O cidadão que ao sair de casa depara-se com numerosas patrulhas de policiais e militares nas ruas, que é filmado em locais públicos, tem suas conversas oficialmente ou clandestinamente gravadas, é monitorado através do controle de seus gastos com cartões eletrônicos, pode se sentir seguro, mas ao mesmo tempo ameaçado, sentindo que pode ser alvo de uma ação violenta, de processos kafkianos ou até de uma bala perdida. Partindo dessa premissa, podemos afirmar que o objetivo do Estado não é só garantir a segurança ou a liberdade, mas manter o complexo e delicado equilíbrio de ambas, justificando sempre sua atuação e as restrições impostas às liberdades.

A promessa de segurança pode dar lugar à afirmação do poder do Estado em momentos de crise. É o que aconteceu nos EUA e em muitos países europeus após os atentados de 11 de setembro de 2001. Com base no medo e na necessidade de segurança, os governos implantaram uma série de medidas de limitação de liberdades individuais em nome

F, 2006, p. 30, com referência a escritos de Horkheimer.

9 A, 1999, p. 707.

10 A, 1999, p. 707. 
da segurança, aumentando os poderes de órgãos de inteligência e das autoridades policiais. Essa campanha de segurança perdura no tempo ${ }^{11} \mathrm{e}$ contribui para a legitimar a atuação autoritária-repressiva do governo dos Estados. $^{12}$

Podemos pensar que um nível máximo de segurança seria atingido se todos os indivíduos fossem controlados pelo Estado, através de câmaras filmadoras, escutas telefônicas, combinação de informações contidas em bancos de dados e legiões de policiais. Mas essa segurança máxima significaria praticamente o fim das liberdades de opinião, de locomoção, de reunião, de associação, de pensamento, levando ao fim do individualismo próprio das sociedades modernas.

\subsection{Segurança pelo bem-estar}

Independentemente desse problema de equilíbrio entre a segurança e os demais direitos, devemos destacar a unilateralidade do conceito de segurança, que, no senso comum e na mídia, relaciona-se quase exclusivamente com a violência urbana e as ameaças terroristas. Esse conceito é discriminatório, selecionando como destinatários-beneficiários da segurança grupos sociais privilegiados, tendo seu patrimônio e incolumidade física protegidas pelo Estado contra riscos de agressão externa ou em razão da criminalidade violenta. Tal conceito de segurança não abrange os grupos socialmente inferiorizados, que não se preocupam de maneira prioritária com a segurança patrimonial e sim com aspectos materiais de satisfação de suas necessidades humanas. ${ }^{13}$

11 Em 10 de julho de 2008 entrou em vigor nos EUA uma lei que muda as normas que regulam as escutas telefônicas. "O texto também garante imunidade às companhias telefônicas que ajudaram Washington a espionar norte-americanos em possíveis casos de terrorismo. O presidente descreveu a medida como "uma lei chave, que é vital para a segurança de nossos cidadãos". O projeto foi discutido de modo acalorado no Congresso durante meses sendo debatidas questões como a privacidade e as liberdades civis dos cidadãos em um quadro de medidas para se evitar ataques terroristas" (Gazeta do Povo, 14 de setembro de 2008 .

12 Nos EUA, juristas conservadores defendem a política do Executivo estadunidense em nome do valor da segurança. Cf. Eric Posner e Vermeule, 2007, assim como Richard Posner, 2006. Cf., em contrapartida, as críticas baseadas em argumentos liberais em Ackerman, 2007 e em argumentos socialistas em Chomsky, 2003. Para o problema na Europa, cf. o panorama em Cottey, 2007.

13 Cf. a crítica em Baratta, 2000; Sarlet, 2005, p. 337, 342; Sabadell, 2007, p. 344. 
Para evitar a unilateralidade, faz-se necessário redimensionar o conceito, pensando na segurança não somente em termos de confronto entre defensores da ordem e agressores, mas também em termos de políticas públicas de garantia dos direitos sociais. O desempregado se sente tanto inseguro quanto o rico empresário que teme os "bandidos". Mas quando os políticos e jornalistas lamentam a insegurança e clamam por políticas "tolerância zero" contra os que ameaçam, não se referem à insegurança dos desempregados nem pedem "tolerância zero" para os empresários que os demitiram.

Pensando no desigual acesso aos recursos sociais que provocam a insegurança dos excluídos, o conceito de segurança pública se modifica necessariamente: "o Estado deve fornecer as condições necessárias para a efetiva tutela de todos os direitos fundamentais, incluindo os direitos coletivos e sociais, e atendendo às necessidades de todos os titulares desses direitos". ${ }^{14}$

Nessa perspectiva, a segurança relaciona-se com o bem estar, dando base a uma série de exigências relativas às principais causas de insegurança: desemprego, acidentes, deterioração do meio ambiente, falta de alimentação adequada e, em geral, não satisfação de necessidades humanas, materiais e imateriais.

A segurança pelo bem-estar não constitui um direito social específico, ao lado dos demais. Abrange todos os direitos sociais, cuja satisfação é fator de segurança dos indivíduos. Nesse sentido, a segurança indica a finalidade, o processo e o resultado da satisfação das necessidades humanas.

No âmbito da segurança pelo bem estar, devemos destacar a segurança alimentar. $\mathrm{O}$ termo designa a situação de regular e permanente acesso a alimentos de qualidade satisfatória e quantidade suficiente, promovendo a saúde, respeitando a diversidade cultural e os imperativos da sustentabilidade ambiental, cultural e econômica. Esse é o conceito estabelecido pelo artigo 3o da Lei no 11.346 de $2006^{15}$ que criou o Sistema Nacional de Segurança Alimentar e Nutricional e tem por objetivo assegurar o direito humano à alimentação adequada.

14 S, 2007, p. 343; Sarlet, 2005, p. 342; cf. extensivamente, Baratta, 2000.

15 Artigo $3^{\circ}$ da Lei no 11.346 de 2006. 
Esse enfoque da segurança não estabelece somente o direito mínimo de alimentação ("fome zero"). Abrange um conjunto de normas sobre a produção, transporte e armazenamento de produtos, com a finalidade de oferecer produtos adequados ao consumo. ${ }^{16} \mathrm{E}$ essa inclusive a justificativa de muitos países para a imposição de "barreiras sanitárias" contra importações de produtos. ${ }^{17}$

\subsection{Dependência conceitual da segurança}

A segurança é um direito à proteção por meio de normas e ações do poder público contra atos de particulares e do próprio poder público quando houver violação ou ameaça de violação dos diversos direitos pessoais. ${ }^{18}$ Isso indica que a segurança não possui conteúdo próprio. É um direito de segundo grau, "acessório" ou "secundário". ${ }^{19}$ Quando pensamos no conceito de segurança, temos sempre em mente outro direito ameaçado ou violado, integridade física, saúde, patrimônio, privacidade, alimentação ou qualquer outro. Mas, em todos os casos, a segurança se refere à satisfação de outro direito. Por isso, foi sugerido não se referir ao "direito à segurança" e sim às condições fáticas e jurídicas (políticas públicas e existência de normas jurídicas) que permitem garantir a "segurança dos direitos". ${ }^{20}$

Torna-se clara a necessidade de adotar um conceito holístico de segurança que evita discriminações de certos grupos sociais ou que privilegie certos direitos. Nesse sentido, há autores que se referem à segurança humana como conceito que abrange reivindicações e políticas públicas voltadas a evitar todas as situações de insegurança de indivíduos ou grupos, independentemente de sua causa. ${ }^{21}$

Nessa ótica, a segurança se define como situação na qual um direito é garantido de maneira permanente e em um nível satisfatório. Sente-

\footnotetext{
16 Maluf, 2007. Sobre as políticas do Governo Federal para a implementação da segurança alimentar, cf. https://www.planalto.gov.br/Consea/exec/index.cfm.

17 Nesse sentido, temos o estabelecimento de uma série de regras restritivas pela União Europeia em nome da segurança alimentar: cf.

18 S, 2007, p. 277.

19 B, 2000, p. 1.

20 B, 2000, p. 3.

$21 \mathrm{~S}, 2005$.
} 
se inseguro quem, em razão de uma crise econômica, não tem certeza se receberá o salário no final do mês (insegurança causada pela falta de regularidade, impedindo a satisfação permanente), assim como quem recebe salário que não atende às suas necessidades básicas (insegurança causada pelo nível insuficiente de satisfação do direito).

\section{Aspectos principais do direito à segurança}

Para muitos operadores do direito, a segurança se relaciona de maneira quase exclusiva com a segurança jurídica, isto é, com a (relativa) estabilidade do sistema normativo no tempo e à (relativa) previsibilidade das decisões das autoridades estatais com base nas normas vigentes. Mas a segurança jurídica é tão somente um aspecto - o melhor estudado no Brasil - do direito à segurança. ${ }^{22}$ Apresentaremos em seguida considerações sobre os aspectos menos estudados do direito à segurança.

\subsection{Tutela estatal da segurança: seguridade social, segurança no trabalho, garantia da propriedade privada, segurança pública}

A seguridade social no Brasil garante várias formas de auxílio a pessoas que se encontram em situação de fragilidade: políticas públicas de saúde; aposentadoria por idade, por invalidez ou por tempo de contribuição; aposentadoria especial; auxílio-doença; auxílio-acidente; auxílio-reclusão; pensão por morte; salário-maternidade; salário-família. Temos ainda a segurança pela renda mínima e demais formas de apoio a pessoas desamparadas para propiciar condições de vida digna.

A Constituição Federal, definindo a seguridade social no artigo 194 confirma que a segurança não possui conteúdo próprio, mas visa a assegurar outros direitos: "A seguridade social compreende um conjunto integrado de ações de iniciativa dos poderes públicos e da sociedade, destinadas a assegurar os direitos relativos à saúde, à previdência e à assistência social".

Isso indica que o direito à seguridade apresenta aspectos secundários de direito à segurança pela força (medidas coativas do Estado, que fiscaliza

22 S, 2007; B, 2007. Cf. a maioria dos estudos nas coletâneas: S (Org.), 2007; R (Org.), 2005. 
e pune, por exemplo, a falta de segurança no trabalho) e aspectos básicos de direito à segurança pelo bem-estar: "A finalidade da Previdência Social é proteger e oferecer segurança aos trabalhadores nos momentos cruciais de sua vida", afirma o Ministério da Previdência Social. ${ }^{23}$

Além da seguridade social temos a segurança no trabalho. Os acidentes são uma das formas mais comuns de atuação do direito em razão de problemas de segurança. Uma ideia básica é que a vida social causa acidentes, e a meta econômica de maior produção em menor tempo os aumenta. A atuação do Estado através dos mecanismos de seguridade compensa as inseguranças e os danos advindos dos riscos das atividades laborais. ${ }^{24}$

Os danos gerados pela insegurança nos processos de produção são danos sociais, devendo as vítimas serem ressarcidas, ainda que os danos não possam ser imputados a certa pessoa. A insegurança apresenta risco de lesão a direitos fundamentais, e a Constituição prevê (artigo $5^{\circ}$, $\mathrm{XXXV)}$ que a lei não excluirá de sua apreciação lesão ou ameaça de lesão de direito. Nesse caso, a sociedade se responsabiliza independentemente da qualidade da conduta (culpa/dolo). ${ }^{25}$ Logo, o Estado responde pelo risco caudado pelo processo de produção de riquezas.

Cabe ao Estado fiscalizar e sancionar a falta de segurança do trabalhador. Também pode impor multas e penalidades de natureza inibitória, na busca de dar efetividade do direito à segurança. Na seguinte decisão é citada a possibilidade de multa de natureza inibitória relacionada ao simples risco da atividade. ${ }^{26}$

A Lei no 8.212 de 1991 fixa critérios para determinar os graus de risco causados pelas empresas com base em estatísticas de acidentes de trabalho, no intuito de prevenir, sancionar e reparar a falta de segurança. Na prática, no entanto, o Estado não consegue de maneira plena manter a promessa de segurança com prestações reais ou mediante a criação e implementação de normas protetoras. Há um evidente desequilíbrio na qualidade de vida e na sensação de segurança de quem tem a capacidade

${ }^{23}$ http://www.previdenciasocial.gov.br/pg_secundarias/beneficios.asp.

${ }^{24}$ A, 1999, p. 708.

25 A, 1999, p. 708.

${ }^{26}$ Cf., por exemplo, TRT 3a Região, RO 01146-2004-086-03-00-4, Quarta Turma, Rel. Juiz Luiz Otávio Linhares Renault, Julg. 26-09-2007, DJMG 06-10-2007. 
econômica de se assegurar no setor privado (aposentadoria, convênios médicos) e de quem deve se contentar com o sistema estatal. Isso indica uma crucial falha/falta no sistema da seguridade social.

A propriedade particular é percebida socialmente e juridicamente como elemento de segurança. O tão explorado "sonho da casa própria" mostra que a propriedade funciona como elemento estabilizador, conferindo maior tranquilidade ao indivíduo. A sensação de segurança aumenta conforme a pessoa adquire maior prestígio e efetivo poder graças ao acúmulo patrimonial.

Por outro lado, a propriedade particular é um dos elementos que geram insegurança, criando desigualdades e sendo o principal mecanismo de exclusão social. Em perspectiva macrossocial, a propriedade particular desestabiliza, marginaliza. Essa leitura crítica do direito de propriedade como elemento literalmente anti-social pode ser encontrada em obras de Rousseau e foi desenvolvida com rigor analítico nos estudos marxistas. ${ }^{27}$

Do ponto de vista da dogmática constitucional, a garantia da propriedade privada não é um dever do Estado no sentido da obrigação de garantir um mínimo de propriedade aos necessitados. Mesmo quando a Constituição impõe ao Estado o dever de garantir aos particulares o direito à moradia, não o obriga a conferir título de propriedade aos beneficiários, isto é, não cria um direito à propriedade. ${ }^{28}$ Dito de maneira diferente, $\mathrm{o}$ Estado não deve garantir a propriedade enquanto direito social.

Pergunta-se se há um dever estatal de preservar, ao menos, a propriedade já constituída, isto é, de assegurar a propriedade enquanto direito individual negativo. A resposta é afirmativa e decorre diretamente do artigo 5ㅇ, XXII: "é garantido o direito de propriedade". Isso significa que o Estado não pode afetar a propriedade privada fora das hipóteses previstas na própria Constituição (desapropriação, tributação etc.). Mas essa garantia estende-se também ao dever de assegurar a propriedade contra agressões de terceiros?

A jurisprudência não vinha considerando que a falta de segurança patrimonial que enseja danos ao proprietário acarreta responsabilidade civil do Estado; restringia a responsabilidade ao fornecedor conforme

27 B, 2004, p. 20-26.

${ }^{28} \mathrm{~S}$, 2003, p. 116-117. 
verificar em algumas decisões. O Supremo Tribunal Federal, ao julgar pedido de indenização em razão de assalto ocorrido em banco, restringiu a responsabilidade, adotando a teoria da responsabilidade subjetiva. Assim sendo, foi afastada a responsabilidade do Estado por falta de segurança, isto é, por descumprimento da obrigação constitucional constante do artigo 144 da Constituição Federal (a segurança como responsabilidade do Estado).

Pelo fato de a segurança pública ser dever do Estado, isso não quer dizer que a ocorrência de qualquer crime acarrete a responsabilidade objetiva dele, maxime quando a realização deste é propiciada, como no caso entendeu o acórdão recorrido, pela ocorrência de culpa do estabelecimento bancário, o que, consequentemente, ensejou a responsabilidade deste com base no artigo 159 do Código Civil. Inexiste, pois, no caso, a alegada ofensa frontal ao artigo 144 da Constituição. ${ }^{29}$

O mesmo entendimento se dá em caso de roubo cometido por fugitivos de presídios:

Responsabilidade civil do Estado. Dano decorrente de assalto por quadrilha de que fazia parte preso foragido vários meses antes - A responsabilidade do Estado, embora objetiva por força do disposto no artigo 107 da Emenda Constitucional no $1 / 69$ (e, atualmente, no parágrafo $6^{\circ}$ do artigo 37 da Carta Magna), não dispensa, obviamente, o requisito, também objetivo, do nexo de causalidade entre a ação ou a omissão atribuída a seus agentes e o dano causado a terceiros. [...] O dano decorrente do assalto por uma quadrilha de que participava um dos evadidos da prisão não foi o efeito necessário da omissão da autoridade pública que o acórdão recorrido teve como causa da fuga dele, mas resultou de concausas, como a formação da quadrilha, e o assalto ocorrido cerca de vinte e um meses após a evasão. ${ }^{30}$

29 STF, AI 239.107, Relator Ministro Moreira Alves, Julg. 19-10-99, Primeira Turma, DJ 12-11-99.

30 STF, RE 130.764, Relator Ministro Moreira Alves, Julg. 12-05-92, Primeira Turma, DJ 07-08-92. 
Esse posicionamento causa perplexidade. Se a segurança pública não for responsabilidade do Estado, será responsabilidade de quem? E se for afastada a responsabilidade do Estado, por que respondem as empresas privadas inclusive pelo dano moral ${ }^{31}$

O Supremo Tribunal Federal dá sinais de que seu entendimento sobre o tema sofre mudanças, conforme verificamos na decisão de 2008. ${ }^{32}$ A Suprema Corte deferiu antecipação de tutela contra o Estado de Pernambuco para pagamento de despesas necessárias para realização de tratamento médico a cidadão que ficou paraplégico em razão de assalto ocorrido em via pública. Fundamento da decisão foi a omissão permanente e reiterada do Estado de Pernambuco em seu dever de prestar serviço adequado de policiamento ostensivo nos locais passíveis de práticas criminosas violentas. Isso gera o dever de indenizar por não ter promovido a segurança, pela falta do serviço, sendo essa a causa que gerou o efeito. A relatora, Ministra Ellen Gracie, indeferia o pedido com base na falta de provas. Foi vencida pela maioria que seguiu voto do Ministro Celso de Mello: "O que não tem sentido é que o estado permaneça simplesmente se omitindo no dever constitucional de prover segurança pública ao cidadão e, depois, demitindo-se das conseqüências que resultam do cumprimento desse mesmo dever". 33

Concluímos que o Judiciário apresenta perspectiva de mudanças em sua linha de entendimento no que tange à responsabilidade civil do Estado e relação à segurança dos bens, estando prestes a ultrapassar o entendimento que manteve durante muitos anos, de que as agressões criminosas a direitos fundamentais não são juridicamente imputáveis a falhas de policiamento e segurança, mas decorrem da decisão e atuação de indivíduos que desrespeitam limites impostos pela lei.

Segundo recente orientação do Supremo Tribunal Federal, o Estado deve estar mais presente em locais com elevado risco de agressões; por exemplo, nas ruas comerciais no centro das cidades ou nos jogos de futebol de times populares. Sem a presença reforçada e ostensiva dos agentes de segurança em tais locais, é possível responsabilizar o Estado por omissões.

31 Cf. C, 2007.

32 STA 223, rel. orig. Min. Ellen Gracie, rel. para acórdão Min. Celso de Mello, j. 14-42008.

33 STA 223, trecho citado conforme notícia consultada no site do Supremo Tribunal Federal em 4-4-2009. 
Por outro lado, devemos considerar as peculiaridades dos casos, não sendo correto admitir o dever do Estado de promover em todas as situações uma segurança absoluta. Atribuir ao Estado o dever de garantir a segurança absoluta da pessoa e de seus bens comprometeria gravemente outros direitos fundamentais, como a liberdade, a intimidade e a privacidade. Significaria exigir que todas as pessoas fossem constantemente acompanhadas de um policial - sem pensar na necessidade de multiplicar ao infinito o número de policiais, caso se decida "guardar os guardiões". Como imputar responsabilidade ao Estado a qualquer omissão, sabendo-se que uma pessoa pode realizar em assalto ao semáforo ou matar alguém com uma faca de cozinha? Temos um caso fortuito, em razão da impossibilidade de prever e impedir sua ocorrência dentro dos limites da razoabilidade.

Já a responsabilidade pela segurança decorrente da prestação de serviço de bancos (e outros estabelecimentos comerciais) é muito mais abrangente e aumenta na medida em que a atividade acarreta tipicamente maiores riscos. Vem sendo pacificamente aceita pelos Tribunais conforme a jurisprudência já citada. Qualquer pessoa que ingressa na agência de um banco, ainda que não seja correntista, é considerada (e protegida) como consumidor. Os bancos prestam serviços de utilidade pública à população em geral, devendo esses serviços ser adequados, eficientes e seguros. O artigo 14, § 1o do CDC qualifica como defeituoso o serviço que não garante a segurança esperada.

Finalmente, a segurança pública é dever do Estado é realizada pela prevenção e repressão de condutas consideradas nocivas à sociedade. $\mathrm{O}$ artigo 144 da Constituição Federal estabelece que "A segurança pública, dever do Estado, direito e responsabilidade de todos, é exercida para a preservação da ordem pública e da incolumidade das pessoas e do patrimônio".

A convivência social e o gozo dos direitos exigem segurança. $\mathrm{O}$ direito à segurança se estende a todo indivíduo, inclusive aos presos que sofrem suspensão de sua liberdade de locomoção e não de todos os direitos fundamentais. Vale lembrar o expresso reconhecimento constitucional do dever estatal de garantir a segurança dos presos: "artigo 5o, XLIX. É assegurado aos presos o respeito à integridade física e moral". 
O preso (e o menor infrator) ficam sob tutela do Estado que responde por eventuais agressões ocorridas em presídios.

A morte de detento por companheiros de cárcere, decorrente de conduta omissiva do Estado que deixou de tomar medidas hábeis a evitar o homicídio, enseja sua responsabilidade pelo evento danoso. Aplicação da teoria da responsabilidade civil objetiva decorrente do nexo de causalidade entre a conduta omissiva e o dano. Devida a indenização pelos danos morais e materiais sofridos. ${ }^{34}$

Via de regra, exige-se a comprovação de culpa ou o dolo da administração penitenciária. Mas o simples fato de superlotação de presídios, que dificulta o controle e aumenta o risco de agressões, indica a omissão culposa do poder público. Se há necessidade de mais vagas em presídios, o Estado deve providenciá-las e não simplesmente aumentar o número de presos sem possibilidade de garantir os diretos das pessoas custodiadas. Em recente decisão, o STJ seguiu a teoria do risco administrativo, responsabilizando o Estado. Foi decidido que o Estado tem responsabilidade civil por suicídio de preso, pois configura culpa in vigilando. A pessoa encarcerada não deveria ter acesso a instrumentos que permitissem o suicídio. Se isso ocorrer, deve ser imputada omissão culposa das autoridades de segurança. ${ }^{35}$

\subsection{Segurança dos indivíduos em relação a interferências estatais}

Em muitas situações, o indivíduo precisa ser protegido do próprio Estado. Os direitos civis e políticos, denominados "de primeira geração" e de cunho individualista, firmam-se como direitos do indivíduo diante Estado, mais especificamente como direitos de defesa ou resistência, demarcando uma zona de não intervenção do Estado à autonomia individual. ${ }^{36}$ São os direitos à vida, à propriedade, à igualdade perante a lei, complementados por uma série de liberdades (expressão, imprensa, reunião, associação etc.).

34 TJ-MG, Apel. Cível - Reexame necessário 1.0024.03.031232-6/001, 5a Câmara Cível, Rel’ Des ${ }^{\mathrm{a}}$ Maria Elza de Campos Zettel, julg. 06/07/2006, DJMG 04/08/2006.

35 STJ, Recurso Especial 847687, 1aㅡ Turma, Rel. Min. José Delgado, julg. 17-10-2006. Disponível em: $<$ https://www.stj.jus.br/revistaeletronica/ita.asp?registro=200601282991 \&dt_publicacao $=25 / 06 / 2007>$.

36 D; M, 2007, p. 64-67. 
Inversamente, a garantia da segurança pode gerar para o Estado um dever de coerção e limitação da liberdade de determinados indivíduos. Ora, se a liberdade individual pode ser restringida com base no direito à segurança, cabe ao Poder Judiciário resolver de maneira definitiva o conflito, de maneira fundamentada.

Exemplificaremos isso com referência ao direito à privacidade. Ninguém admite que, em prol da segurança coletiva, seja aniquilado o direito à privacidade; tampouco se pode admitir que esse último direito possa ser erigido em óbice absoluto de medidas interventivas do Estado. A doutrina e jurisprudência nacional pouco se dedicam ao assunto, limitando-se a reproduzir afirmações genéricas, como a necessidade de tutelar a vida privada, mas sem atribuir a ela um peso absoluto que favoreceria a impunidade. Admite-se a "ponderação" para flexibilizar a privacidade diante do imperativo de proteger outros direitos fundamentais e interesses gerais em casos excepcionais. ${ }^{37}$

Mas o debate carece de substância teórica. Ao invés de afirmar genericamente a possibilidade de flexibilização do direito à privacidade, é necessário realizar o controle de conformidade constitucional das normas infraconstitucionais que objetivam preservar a segurança (ou outros direitos). Tais normas podem ser inconstitucionais, por excesso de medidas restritivas de liberdades de maneira não justificada.

Esse trabalho de verificação da constitucionalidade consiste basicamente na verificação da necessidade e adequação de cada restrição imposta às liberdades individuais para tutelar a segurança coletiva, devendo sempre existir justificativa constitucionalmente aceita para tanto. ${ }^{38}$ Esse trabalho é particularmente árduo, havendo o risco de o julgador realizar avaliações subjetivas. Mas, independentemente dos problemas de racionalidade do exame judicial da constitucionalidade, ${ }^{39}$ é necessário constatar o conteúdo de cada direito fundamental envolvido no problema dos limites da intervenção estatal. Sem conhecer os setores de atividade humana protegidos por cada direito fundamental não é possível avaliar suas restrições.

37 B, 2002, p. 220-223, 267-277.

${ }^{38}$ Cf. F J, 2006, p. 211.

${ }^{39}$ D; M, 2007, p. 224-232. 
No âmbito da delimitação do direito à privacidade ${ }^{40}$ é interessante examinar, ainda que brevemente, a contribuição da jurisprudência constitucional alemã. O Tribunal Constitucional Federal, analisando a área de proteção do direito de privacidade, distinguiu entre a dimensão de conteúdo e a espacial. ${ }^{41} \mathrm{Na}$ dimensão de conteúdo, o Tribunal define a privacidade como o direito de personalidade de alguém que deve ter a possibilidade de ficar só e de ser "ele mesmo", fora da observação e do controle social exercido por outras pessoas. ${ }^{42}$

No que diz respeito ao espaço físico tutelado, o Tribunal afirma que, em geral, protege-se como lugar de privacidade a residência efetiva de certa pessoa ("casa" no sentido amplo). Mas essa delimitação não é absoluta, podendo ter como espaço tutelado também o jardim, um estacionamento particular e outros lugares. Mas, seguramente, não se pode alegar exercício da privacidade em lugares publicamente acessíveis, ${ }^{43}$ ainda que de propriedade particular.

Seria necessária uma maior reflexão sobre a delimitação espacial da privacidade em casos de emprego de métodos de monitoramento não convencionais como os dispositivos de escuta ambiental ou filmagem, instalados sem conhecimento dos frequentadores de certo local, no intuito de apurar ou impedir crimes e de aumentar a segurança. Isso foi reconhecido em outras decisões do Tribunal, que tutelam informações pessoais independentemente das circunstâncias e do lugar no qual foram colhidas. ${ }^{44}$

No caso do Brasil, a Lei no 9.296, de 1996, que regulamenta as interceptações telefônicas, apresenta muitos problemas de constitucionalidade, entre os quais indicamos a obrigação de o juiz decidir sobre pedido de interceptação telefônica no prazo de 24 horas, o que dificulta o exame circunstanciado do pedido. A constitucionalidade da Lei foi questionada

40 Sobre o conteúdo constitucionalmente tutelado do direito à privacidade. cf. M, 1995; A, 1996; S, 1998.

41 Posições extraídas da decisão "Carolina II" do Tribunal Constitucional Federal alemão. Entscheidungen des Bundesverfassungsgerichts (coletânea oficial), vol. 101, p. 361-396. Texto disponível na internet em: http://www.oefre.unibe.ch/law/dfr/bv101361.html.

42 Entscheidungen des Bundesverfassungsgerichts (coletânea oficial), v. 101, p. 367, 371-372.

43 Entscheidungen des Bundesverfassungsgerichts (coletânea oficial), vol. 101, p. 365-366.

44 Entscheidungen des Bundesverfassungsgerichts (coletânea oficial), v. 65, p. 45; v. 95, p. 241; v. 109, p. 279. Cf. os comentários em M, 2004. 
várias vezes e recentemente foi interposta perante o Supremo Tribunal Federal a ADIN no 4.112, ainda pendente de julgamento.

Igualmente preocupantes são as notícias sobre os abusos na interceptação telefônica, que ocorrem nos últimos anos no Brasil. Conforme estimativas do presidente da Associação de Servidores da Agência Brasileira de Inteligência, cerca de trezentas mil pessoas têm o telefone grampeado, ocorrendo apenas quinze mil escutas com a devida autorização judicial. Basta acompanhar o noticiário para constatar que as informações sobre muitas investigações policiais são acompanhadas da transmissão ou transcrição de trechos "comprometedores" provenientes de escutas clandestinas. ${ }^{45}$

As escutas realizadas por órgãos estatais sem autorização constituem prática comum que deu ensejo à CPI das "Escutas Telefônicas Clandestinas". ${ }^{46}$ Tais escutas afetam inclusive autoridades estatais, e incluíram recentemente o grampeamento do telefone do presidente do Supremo Tribunal Federal com possível envolvimento de funcionários do Executivo federal e tendo provocado o afastamento de dirigentes da Agência Brasileira de Inteligência. ${ }^{47}$ Trata-se de prática que não se baseia, evidentemente, na ponderação entre direitos fundamentais. Concede tacitamente a primazia axiológica à segurança ("combate eficiente ao crime", "os fins justificam os meios") sob os aplausos da mídia e da opinião pública e permite que sejam violados direitos de maneira injustificada. Nesse caso, a invocação da segurança é meramente retóricopolítica, sendo feita contra legem.

Em paralelo, há fortes críticas à prática do Poder Judiciário, que autoriza escutas sem indícios suficientes, por tempo praticamente ilimitado e, muitas vezes, sem respeitar as regras de competência. ${ }^{48}$ Noticiou-se que, em 2007, foram realizadas escutas em mais de quatrocentos mil

45 Informações conforme reportagem da Revista Época: "Você está sendo grampeado?" http://revistaepoca.globo.com/Revista/Epoca/0,EDR79786-6009,00.html.

46 As atas das sessões da CPI podem ser consultadas em: http://www2.camara.gov.br/ comissoes/temporarias53/cpi/cpiescut/notas-taquigraficas.

47 Cf. a reportagem e a entrevista do Presidente do Supremo Tribunal Federal Min. Gilmar Mendes em Passos, 2008.

48 Cf. as críticas formuladas pelo Presidente do Superior Tribunal de Justiça Min. Cesar Asfor Rocha contra os abusos que transformam as escutas em "devassas" em H, 2008. 
casos com autorização do Judiciário, ${ }^{49}$ tendo recentemente o Conselho Nacional de Justiça criado um programa de monitoramento das decisões que permitem as escutas, no intuito de sua limitação. ${ }^{50}$

Nesse caso também temos uma "precompreensão" a favor da segurança e contra a privacidade sem decisões fundamentadas em ponderação racional. Faz parte dessa tendência a facilidade de decretar prisões com base em dados pouco confiáveis. Foi relatado o caso de empresário que passou onze dias preso durante a Operação Anaconda, libertado depois de o advogado ter demonstrado que as conversas suspeitas eram feitas por outra pessoa, tendo a União sido condenada a pagar indenização de R $\$ 500$ mil ao empresário, uma vez que o Estado, em nome da segurança, violou o direito à privacidade. ${ }^{51}$

\section{Conclusão}

Ninguém discorda da necessidade de garantir altos padrões de segurança. Mas as políticas públicas que visam a atingir essa meta devem ponderar as eventuais consequências da intervenção do Estado em direitos fundamentais em nome da segurança pública. Trata-se da necessidade de pensar no custo jurídico e político da segurança. Deve também ser levado em consideração o fato de que as práticas de vigilância em prol da segurança de alguns fragilizam a segurança dos alvos de operações para garantir a segurança pública.

Surge em paralelo a necessidade de pensar na segurança em termos de garantia efetiva do bem-estar de todos, cabendo aqui um cálculo em termos de custo econômico para estabelecer as prioridades nas políticas públicas, e justificando a distribuição e a intensidade dos deveres do Estado, que começa a ser chamado a responder mais efetivamente pelo direito à segurança conforme a citada decisão do Supremo Tribunal Federal que confirma o direito individual de exigir do Estado a garantia da segurança pública.

\footnotetext{
$49 \mathrm{http} / /$ www.conjur.com.br/static/text/69687.

50 Conselho Nacional de Justiça, Resolução no 59 de 9-9-2008; disponível em http:// www.cnj.jus.br/index.php?option=com_content\&task=view\&id=4872\&Itemid=160.

51 Informações conforme reportagem da Revista Época: "Você está sendo grampeado?" http://revistaepoca.globo.com/Revista/Epoca/0,,EDR79786-6009,00.html.
} 
No âmbito da teoria dos direitos fundamentais, a utilização do princípio da proporcionalidade é uma das formas de estabelecer os limites para harmonizar o exercício dos direitos, mostrando a adequação e a necessidade de certas intervenções, conforme argumentação racional. Em paralelo, faz-se necessária a elaboração de normas sobre as hipóteses de admissão de intervenções em direitos fundamentais em prol da segurança, estabelecendo critérios com respeito ao princípio da igualdade, garantindo transparência e limitando a discricionariedade do Judiciário e dos órgãos de segurança.

Enquanto não se cumpre, a norma constitucional é apenas uma promessa de regularidade, uma promessa de direito, de um compromisso que eventualmente será honrado. Estudar os vários aspectos do direito à segurança é uma forma de criticar práticas jurídicas, problematizando discursos ideológicos e promessas não cumpridas.

\section{Referências}

ACKERMAN, Bruce. Before the next attack: preserving civil liberties in an age of terrorism. New Haven: Yale University Press, 2007.

ARAÚJO, Luiz Alberto David. A proteção constitucional da própria imagem: pessoa física, pessoa jurídica e produto. Belo Horizonte: Del Rey, 1996.

ARNAUD, André-Jean. Segurança. In: ARNAUD, André-Jean (Dir.). Dicionário Enciclopédico de Teoria e de Sociologia do Direito. Rio de Janeiro: Renovar, 1999, p. 707-709.

BALIBAR, Étienne. Le renversement de l'individualisme possessif. In: GUINERET, Hervé; MILANESE, Arnaud (Org.). La propriété: le propre, 1'appropriation. Paris: Ellipses, 2004, p. 9-30.

BARATTA, Alessandro. Sicurezza. Disponível em: <http://www. imageuro.net/mediaterraneo/archivio/encyc/pdf/barat.pdf, 2000>.

BARROS, Marco Antonio de. A busca da verdade no processo penal. São Paulo: RT, 2002.

BIGOLIN, Giovani. Segurança jurídica: a estabilização do ato administrativo. Porto Alegre: Livraria do Advogado, 2007. 
CASTRO, Gustavo Almeida Paolinelli de. Política de segurança pública: o direito à intimidade na era da videovigilância. Fórum Brasileiro de Segurança Pública, v. 2, 2007, p. 82-93.

CHOMSKY, Noam. Power and Terror. Post-9/11 Talks and Interviews. New York: Seven Stories, 2003.

COTTEY, Andrew. The new security in Europe. London: Palgrave, 2007. DIMOULIS, Dimitri; MARTINS, Leonardo. Teoria geral dos direitos fundamentais. São Paulo: RT, 2007.

FONTES Junior, João Bosco Araujo. Liberdades fundamentais e segurança pública. Rio de Janeiro: Lumem Juris, 2006.

FROTA, Ângela. Regime de segurança alimentar na União Européia. Curitiba: Juruá, 2007.

HAIDAR, Rodrigo. País sob escuta. 2008. Disponível em: <http://www. conjur.com.br./static/text/69508>.

MALUF, Renato. Segurança alimentar e nutricional. Rio de Janeiro: Vozes, 2007.

MARTINS, Leonardo. Crime organizado, terrorismo e inviolabilidade do domicílio. Sobre o controle de constitucionalidade de novas regras do direito processual alemão e sua relevância para a interpretação do artigo 5o, IX da CF. Revista dos Tribunais, n. 824, 2004, p. 401-437.

MIGUEL, Carlos Ruiz. La configuración constitucional del derecho a la intimidad. Madrid: Tecnos, 1995.

PASSOS, Anderson. Perigos da Satiagraha. Gilmar Mendes questiona ajuda informal da Abin à PF. 2008. Disponível em: $<$ http://www.conjur. com.br./static/text/69834>.

POSNER, Eric; VERMEULE, Adrian. Terror in the Balance: security, liberty and the courts. Oxford: Oxford University Press, 2007.

POSNER, Richard. Not a suicide pact: The Constitution in a Time of National Emergency. Oxford: Oxford University Press, 2006.

ROCHA, Cármen Lucia Antunes (Org.). Constituição e segurança jurídica. Belo Horizonte: Fórum, 2005. 
SABADELL, Ana Lucia. Segurança (direito à). In: DIMOULIS, Dimitri (Org.). Dicionário brasileiro de direito constitucional. São Paulo, 2007, p. 343-344.

SAMPAIO, José Adércio Leite. Direito à intimidade e à vida privada. Belo Horizonte: Del Rey, 1998.

SANTI, Eurico Marcos Diniz de (Org.). Segurança jurídica na tributação e Estado de Direito. São Paulo: Noeses, 2007.

SARLET, Ingo Wolfgang. Algumas anotações a respeito do conteúdo e possível eficácia do direito à moradia na Constituição de 1988. Cadernos de Direito, n. 5, 2003, p. 107-141.

SARLET, Ingo Wolfgang. Constituição, proporcionalidade e direitos fundamentais. Boletim da Faculdade de Direito, v. LXXXI, Coimbra, 2005, p. 325-386.

SARLET, Ingo Wolfgang. Eficácia do direito fundamental à segurança jurídica. Revista da Escola da Magistratura, Tribunal Regional do Trabalho 2를 Região, 2, 2007, p. 271-310.

SORJ, Bernardo. Segurança, segurança humana e América Lática. Sur, n. 3, 2005. Disponível em: <www.scielo.br>. 